\title{
Management of a Complicated Crown-Root Fracture using Single-Visit Endodontic Treatment and Fiber Post as an Intracanal Anchorage
}

\section{Pradnya Vilas Bansode, Seema Dhananjay Pathak, Rahul Bhikanrao Deore}

\begin{abstract}
This case report describes the management of complicated crown-root fracture of a maxillary central incisor. Initially, the fractured fragment was stabilized by splinting it with composite and wire splint to adjacent teeth. During next appointment single-visit endodontic treatment was performed, the fractured crown portion was reattached using fiber post and composite resin. Success was achieved by normality in function, esthetics, health of tooth and surrounding periodontal structures. This reattachment technique presents several advantages, such as better and long-lasting esthetics, improved function and a positive psychological response, faster and less complicated procedure. The main objective of the presented technique restoration is to provide highly conservative approach that combines esthetics and function. Advantages, disadvantages and prognosis of this treatment approach are discussed.
\end{abstract}

Keywords: Complicated crown-root fracture, Reattachment, Fiber post.

How to cite this article: Bansode PV, Pathak SD, Deore RB. Management of a Complicated Crown-Root Fracture using Single-Visit Endodontic Treatment and Fiber Post as an Intracanal Anchorage. Int J Prosthodont Restor Dent 2013; 3(1):33-36.

Source of support: Nil

Conflict of interest: None

\section{INTRODUCTION}

Dental trauma is a relatively common condition that presents restorative challenges. It has been reported that approximately $20 \%$ of children experience dental injury to their permanent teeth before leaving school, ${ }^{1}$ and approximately one in six adolescents and one in four adults suffer traumatic dental injury during their lifetime. ${ }^{2,3}$ Majority of dental injuries involve single tooth and mostly maxillary central incisors. ${ }^{4,5}$

Trauma to maxillary incisors is usually associated with overjet, gender, race, ethnicity, contact sports and age. ${ }^{6-8}$ Contact sports account for $49 \%$ of dental injuries. ${ }^{9}$ The most common type of dental injury in permanent dentition is uncomplicated crown fracture accounting for more than $50 \%$ tooth traumas. ${ }^{6}$ The treatment of uncomplicated crown fractures is relatively simple involving recontouring, composite bonding or porcelain veneers. Complicated crown-root fractures on the contrary present challenge to the restorative dentist for its management because of encroachment of biologic width and its subgingival nature.
In case of complicated crown-root fractures, where both the crown and the root are available relatively intact, can be managed by tooth fragment reattachment method, first described by Tennery ${ }^{10}$ and subsequently by Starkey ${ }^{11}$ using acid etch technique. Though not as much predictable, but it is advantageous and should be the option of first choice. The objective of this case report is to present conservative approach for managing complicated crown-root fracture of a maxillary central incisor using single-visit endodontic treatment and fiber post.

\section{CASE HISTORY}

A21-year-old male reported to the department of conservative dentistry with chief complaint of fall from motorbike 7 days back, loosening and slight discomfort on biting with upper anterior tooth. On clinical examination, complicated oblique crown-root fracture was noticed with maxillary right central incisor (Figs 1A and B). A horizontal fracture line was seen on labial side with its palatal subgingival oblique extend (Figs 1A and B). The tooth was tender to vertical percussion, responded negatively to electrical pulp testing and radiographically showed two fracture lines with slight widening of periodontal ligament (PDL) space (Fig. 1C). On the basis of these findings, the diagnosis of complicated crown-root fracture was made and treatment was planned in two phases as emergency and definitive, after taking informed consent of the patient.

\section{Emergency Phase}

The goal of emergency treatment was to achieve esthetics, limited function and comfort. During the first appointment, the fractured fragment was held with finger pressure into its original position and was stabilized to adjacent teeth with composite wire splint for 1 week (Fig. 1D). Patient was instructed to avoid further trauma to the splinted tooth.

\section{Definitive Phase}

One week after the emergency phase when the patient reported, putty polyvinyl siloxane index was prepared to act as reliable positioning guide for reattachment of fragment (Fig. 1E). Under local anesthesia, the splint was removed and conservative labial and palatal gingival flaps were raised by making intrasulcular incisions to separate the fragment 

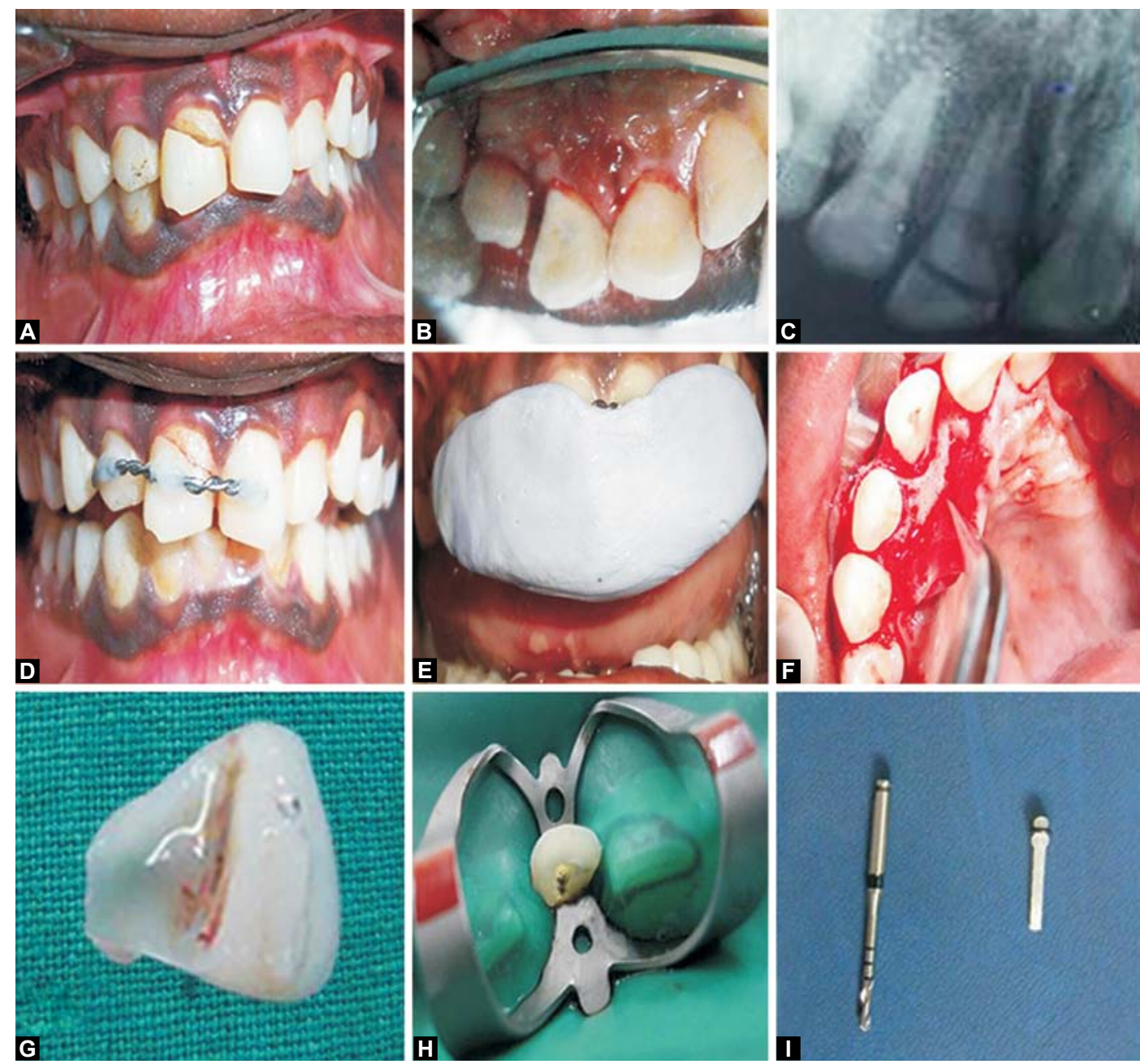

Figs 1A to I: (A) Labial aspect of fracture is noticeable, (B) fracture line not discernible on palatal aspect indicating possible subgingival extent, (C) fracture lines discernible at two levels. Widening of PDL space with 11 can be seen, (D) fractured crown segment, (E) putty polyvinyl siloxane index, $(F)$ conservative labial and palatal gingival flaps raised, $(G)$ fractured fragment, $(H)$ the tooth 11 isolated with rubber dam and retained by \#212 cervical retainer, (I) light transmitting fiber post (FiberLux System, Coltene/Whaledent)

from palatal PDL fibers as well as to determine the extent of fracture line (Figs $1 \mathrm{~F}$ and $\mathrm{G}$ ). After separation of the fragment, it was stored in normal saline and it was observed that the biologic width was not violated avoiding the need for osseous recontouring.

The tooth was isolated with rubber dam retained by \#212 cervical retainer (Fig. 1H) and single-visit endodontic treatment, followed by post space preparation was done to receive a light transmitting fiber post (Fiberlux System, Coltene/Whaledent) (Fig. 1I). The fiber post was cemented inside the canal using self-etch, dual cure resin cement (3M ESPE) (Fig. 2A). The internal aspect of the crown fragment was prepared to accommodate the fiber post; it was then etched, bonded and reattached accurately with resin cement using the silicone index (Fig. 2B). The remaining margins of the fragment were restored with the composite resin, finishing and polishing was done using the Shofu kit. The gingival flaps were repositioned to their original position and sutured with 3-0 black silk (Figs 2C and D). Any occlusal interference was checked and adjusted and immediate postopertive radiograph was obtained (Fig. 2E). Routine postoperative instructions were given.

\section{Follow-up}

Patient was examined after 1 week with the tooth asymptomatic, normal healing of adjacent soft tissues and stable reattached fragment. The sutures were removed and patient was instructed to avoid further trauma to the tooth (Fig. 2F). Follow-up clinical and radiographic examination was also done 1 and half year later with normal function, esthetics and comfort (Figs $2 \mathrm{G}$ and $\mathrm{H}$ ).

\section{DISCUSSION}

The different treatment modalities for management of this situation could be extraction of the tooth followed by singletooth implant, which should be the option of last resort when more conservative and viable treatment options are available. Because of inadequate ferrule in this case, post and core was not possible without orthodontic extrusion/ 

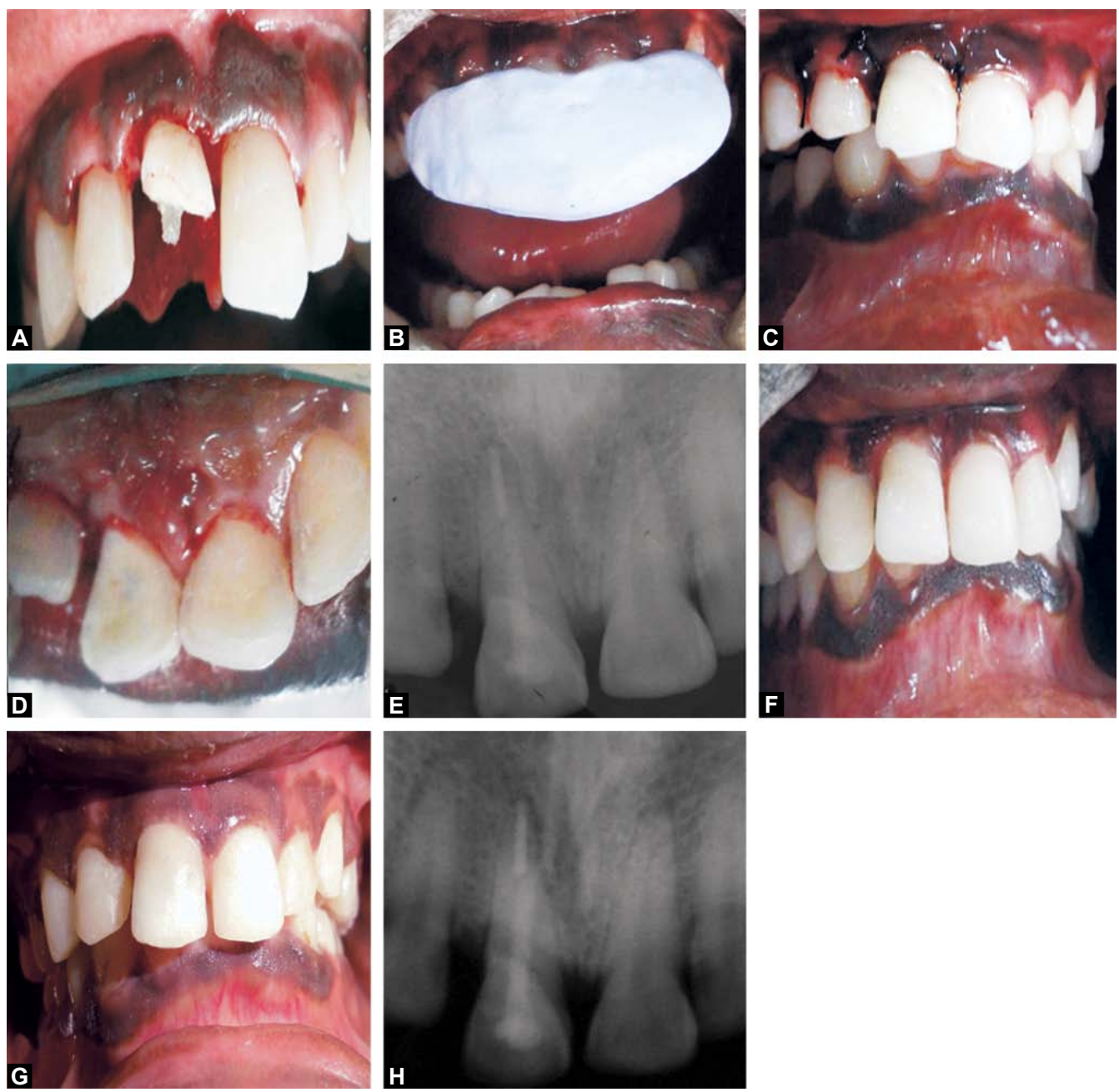

Figs 2A to H: (A) Fiber post luted inside the canal, (B) silicone index used as repositioning guide, (C) labial view immediately after reattachment, (D) palatal view after finishing and polishing of composite, $(E)$ post-treatment radiograph, $(F)$ adequate soft tissue healing, $(\mathrm{G})$ follow-up clinical examination at one and half year later, $(\mathrm{H})$ follow-up radiographic examination at one and half year later

crown lengthening, which would have been resulted in cervical diameter discrepancy as compared to left central incisor and therefore resulting in poor esthetic outcome. The advantages of the reattachment technique that are worth mentioning include most conservative approach, single-visit procedure, use of patient's own tooth as 'natural veneer' maintaining the esthetics and positive psychological impact on the patient. ${ }^{12,13}$

Biological changes in teeth following endodontic treatment leading to reduced hardness and resistance to shearing have been reported. Restoration with a post following endodontic treatment retains a core to support coronal restoration, particularly when tooth loss is extensive. ${ }^{14}$

Use of glass fiber post was essential to support the crown structure coronal to the gingival margin. Fiber post was the logical option as it can be bonded to canal walls, has good physical and mechanical properties, and is esthetic. ${ }^{15,16}$ It has been also postulated that when resin cement is used for luting glass fiber post, its stress distribution pattern reinforces the tooth structure. ${ }^{17}$

\section{Advantages of the Technique}

1. Better esthetics as restoration of same tooth shape and color.

2. Long-lasting esthetics, because a minimum of composite resin remains exposed at the facial area.

3. It is faster and less complicated technique than implant or other alternative.

4. Improved function because anterior guide will be maintained on dental structure causing an amount of an incisal wear equal to that of adjacent teeth which would be more with composite resin or other restoration.

5. A positive emotional and social response from the patient to preservation of natural tooth structure.

6. Fiber post system was selected for good anchorage as it can be bonded to the root canal walls and to the coronal fragment.

7. Glass fiber post is very strong and virtually unbreakable (because of passive retentive slots instead of active cutting threads, providing superior esthetic results because of translucency. 
8. Their elasticity is similar to dentin enabling the post to move and work with natural dentin. ${ }^{15}$

Glass post dissipate the occlusal stress and do not transmit it as metal post do. Glass fiber post consists of strong glass fiber bundles embedded in a special composite material which will mix and naturally binds with dentin and material used for cementing and core build up. The braided platform of glass fiber bundles in a multiaxial arrangement gives the post superior resistance to bending and torsion forces.

Mannoccci et al postulated that dual-cure self-activating system like 3M ESPE showed a more uniform resin tag and resin dentin interdiffusion zone formation along root canal walls than light curing system. Successful bonding minimizes the wedging effect of post within the canal, results in less dentinal removal and leads to lower susceptibility to tooth fracture.

\section{Disadvantages of the Technique}

1. We cannot predict longevity of this technique.

2. There are chances of fracture of post if trauma occurs to same tooth in future.

\section{Indications}

Fracture of crown root which is in restorable position.

\section{Contraindications}

(1) Periodontally weak tooth, (2) multiple fractures difficult to reduce and (3) violation of biological width.

More and more case reports with long-term followups are needed in future to advocate the use of this same technique in different patterns of tooth fractures. With these limitations in mind, still the technique described here is highly conservative, provides adequate function, esthetics.

\section{CONCLUSION}

Traumatic dental injuries are common among children, adolescents and young adults. A conservative restorative option is described as treatment for crown-root fracture. The fragment reattachment was made possible with use of an intracanal fiber post system. The main objective of the presented technique restoration is to provide highly conservative approach that combines esthetics and function.

\section{REFERENCES}

1. Andreason JO, Ravn JJ. Epidemiology of traumatic dental injuries to primary and permanent teeth in a Danish population sample. Int J Oral Surg 1972;1(5):235-239.

2. Kaste LM, Gift HC, Bhatt M, Swango PA. Prevalence of incisor trauma in persons 6 to 50 years of age: United States, 1988-1991. J Dent Res 1996 Feb;75 Sepc No:696-705.
3. Shulman JD, Peterson J. The association between incisor trauma and occlusal characteristics in individuals 8 to 50 years of age. Dent Traumatol 2004 Apr;20(2):67-74.

4. Calişkan MK, Türkün M. Clinical investigation of traumatic injuries of permanent incisors in Izmir, Turkey. Endod Dent Traumatol 1995 Oct;11(5):210-213.

5. Shayegan A, De Maertelaer V, Vanden Abbeele A. The prevalence of traumatic dental injuries: a 24-month survey. J Dent Child (Chic) 2007 Sep-Dec;74(3):194-199.

6. Andreason, JO. Tooth and bone loss related to dental trauma. In: Koch, G.; Bergendal, T.; Kvint, S., editors Consensus conference on oral implants in young patients. Stockholm: ForlagshusetGothia AB; 1996. p. 40-45.

7. Borum MK, Andreason JO. Therapeutic and economic implications of traumatic dental injuries in Denmark: an estimate based on 7549 patients treated at a major trauma center. Int J Paediatr Dent 2001 Jul;11(4):249-258.

8. Glendour U. Epidemiology of traumatic dental injuries: a 12 years review of literature. Dent Traumatol 2009;25:64-68.

9. Huang B, Marcenes W, Croucher R, Hector M. Activities related to the occurrence of traumatic dental injuries in 15 to 18 years olds. Dent Traumatol 2009 Feb;25(1):64-68.

10. Tennery TN. The fractured tooth reunited using the acid-etch bonding technique. Tex Dent J 1978 Aug;96(8):16-17.

11. Starkey PE. Reattachment of a fractured fragment to a tooth: a case report. J Indiana Dent Assoc 1979 Sep-Oct;58(5):37-38.

12. Ramos-Jorge ML, Bosco VL, Peres MA, Nunes AC. The impact of treatment of dental trauma on quality of life of adolescents-a case-control study in Southern Brazil. Dent Traumatol 2007 Apr;23(2):114-119.

13. Ferraz JA, Pécora JD, Saquy PC, Sousa-Neto MD. Treatment of oblique crown fractures in maxillary premolars using adhesive tooth fragment reattachment: 19 years of follow up. Dent Traumatol 2011 Dec;27(6):455-459.

14. Tosun G, Yildiz E, Elbay M, Sener Y. Reattachment of fractured maxillary incisors using fiber-reinforced post: two case reports. Eur J Dent 2012 Apr;6(2):227-233.

15. Tamse A. Iatrogenic vertical root fracture in endodontically treated teeth. Endod Dent Traumatol 1988 Oct;4(5):190-196.

16. de Castro JC, Poi WR, Pedrini D, Tiveron AR, Brandini DA, de Castro MA. Multidisciplinary approach for the treatment of a complicated crown-root fracture in a young patient: a case report. Quintessence Int 2011 Oct;42(9):729-735.

17. Mannocci F, Ferrari M, Watson TF. Intermittent loading of teeth restored using quartz fiber, carbon-quartz fiber and zirconium dioxide ceramic root canal posts. J Adhes Dent 1999 Summer;1(2):153-158.

\section{ABOUT THE AUTHORS}

\section{Pradnya Vilas Bansode}

Associate Professor and Head, Department of Conservative Dentistry Government Dental College and Hospital, Aurangabad, Maharashtra, India

\section{Seema Dhananjay Pathak (Corresponding Author)}

Assistant Professor, Department of Conservative Dentistry Government Dental College and Hospital, Aurangabad, Maharashtra India, Phone: 9850694750, e-mail: seemadpathak@gmail.com

\section{Rahul Bhikanrao Deore}

Dental Surgeon, Department of Conservative Dentistry, Government Dental College and Hospital, Aurangabad, Maharashtra, India 